\title{
Getting the boys involved: Using an interactive questionnaire to investigate Grade 6 boys' writing
}

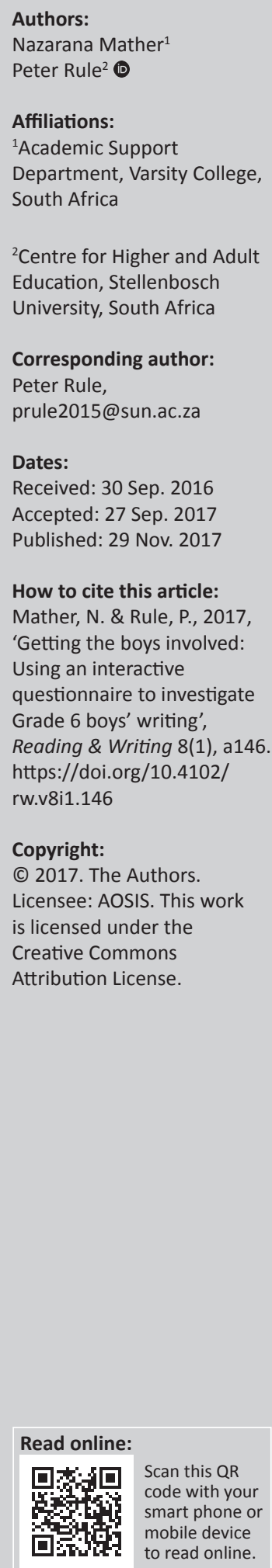

\begin{abstract}
Whilst research has been conducted on reading skills at primary school level in South Africa, not much research exists on writing, especially boys' writing. This article focuses on the use of an interactive questionnaire to get Grade 6 boys involved in research that is based on a cycle of the writing programme as prescribed by the Curriculum and Assessment Policy Statement. Underpinned by literature on research with children and on boys' learning and writing, a questionnaire was developed, piloted and adapted to engage boys actively in the research process and facilitate ease of use. The questionnaire was then administered to 39 Grade 6 boys from two schools in KwaZulu-Natal. An evaluation of the use of the questionnaire found that four key lessons emerged: attention to affective responses, supporting and scaffolding the process, using appropriate multi-modality and using incentives to engage participants. The article argues that careful consideration of the research participants' interests, age, gender and cultural motivation is an important part of affording them agency in the research process.
\end{abstract}

\section{Introduction}

Whilst there is extensive international literature on the teaching of writing at primary school level (Graham 2003; Tan \& Zammit 2016; Vincent 2006), in South African primary schools, reading rather than writing has been a dominant research focus. For instance, studies conducted in South Africa have established that teachers tend to focus on decoding text to speech when developing their learners' reading skills and pay little attention to the development of comprehension and writing skills (Long \& Zimmerman 2008; Mather 2012; Pretorius 2002; Rule \& Land 2017). One of the few South African studies on teaching writing at primary school level, conducted by Nasvaria, Pascoe and Kathard (2011) in the Western Cape, finds that teachers are very concerned about the written language development of their learners. Given this, more research regarding what goes on during writing lessons in South Africa is needed. Writing is integral to all learning; for example, notes and essays have to be written, many formal assessment tasks are written and answers in tests are written, in all learning areas. Thus, if a learner is unable to write at the appropriate level, all learning will be affected.

The purpose of this article is to evaluate the use of an activity-based questionnaire as a data collection tool to research Grade 6 boys' writing development, as well as boys' perceptions of writing instruction, in KwaZulu-Natal (KZN) (one of nine provinces in South Africa). The research took place in the context of a cycle of the writing programme (i.e. the process-genre process of writing), as prescribed by the Curriculum and Assessment Policy Statement (CAPS). According to the CAPS [Department of Basic Education (DBE) 2011a], developing learners' writing skills in the Intermediate Phase (IP) involves leading them through the following stages of the writing process: planning, drafting, revising, editing and publishing. Thus, in Grade 6, learners go through a number of cycles of the writing process throughout the year to complete different pieces of writing such as descriptive essays, letters, emails and instructions. The questionnaire described here was used as part of a larger study, in which writing instruction was investigated in two schools. To collect data for the larger study, interviews with the teachers were conducted, writing lessons were observed, the boys' written efforts and their teachers' feedback were analysed and the boys were given an activity-based questionnaire to complete. Given the purpose of this article, only an analysis of the boys' written, oral and behavioural responses to the interactive questionnaire will be presented; and this analysis will be used to evaluate the questionnaire. In evaluating the questionnaire, we considered four dimensions:

- The content: Were the learners able to understand and engage with the content of the questionnaire? 
- The process: Did the process of administering the questionnaire support learners in responding to it?

- The design: Did the design of the questionnaire facilitate learners' engagement with it?

- The findings: Did the learners' responses to the questionnaire yield useful insights into their writing development?

This article begins by providing the rationale behind the study and the design of the activity-based questionnaire. It then reviews scholarship surrounding boys' learning, in particular how their writing skills develop and how research is conducted with pre-pubescent children, especially boys. This forms a backdrop to the main focus of the article, which is an evaluation of the content, process, design and findings of the activity-based questionnaire, and the lessons learnt from its application.

\section{Rationale for the study}

Boys' writing was selected as the focus of the study because of the fact that boys' language performance (including writing) is a cause for concern in South Africa. Given the centrality of writing in the curriculum, its instruction ought to receive heightened attention. The writing programme prescribed by the CAPS is made up of a number of writing tasks for different purposes, which must be completed during the course of the year, using the process-genre approach to teaching writing (DBE 2011a). This, as explained above, includes at least five stages: planning, drafting, revising, editing and publishing. Very little is known about how South African learners (boys in particular) respond to this instructional approach, and what their perceptions of and attitude to this kind of writing process are.

What is known is that South African children have performed poorly in international literacy tests. For example, according to the Progress in International Reading Literacy Study (PIRLS 2006 cited in Long \& Zimmerman 2008), South African Grades 4 and 5 learners achieved the lowest mean performance scores in comparison with 39 other participating countries. Assessments within South Africa suggest that this poor ranking is credible: in the Annual National Assessment (ANA) tests of 2012 in KZN, Grade 6 learners achieved an average of $43 \%$ in home language (HL) with only $39 \%$ of the learners who wrote obtaining above 50\% (DBE 2012). In 2013, the Department of Basic Education saw an improved 59\% average, and $68 \%$ of learners achieved higher than 50\% (DBE 2013). However, what remained the same in 2012 and 2013 was that boys achieved poorer results than girls in all provinces, in both language and mathematics. For instance, in 2012 in KZN, Grade 6 girls achieved an average of $44.2 \%$ in HL whilst the boys achieved $37.6 \%$ (DBE 2012), and in 2013, the girls achieved $61.4 \%$ whilst the boys obtained 53.3\% (DBE 2013). In 2014, this trend continued in the ANA, with boys achieving an average of 59.2\% and girls achieving an average of $66.4 \%$ (DBE 2014). These results resonate with an earlier report by Howie et al. (2012) which indicated that girls outperform boys in South Africa, in both the prePIRLS and PIRLS 2011 studies.
Studies conducted in Australia (Pavy 2006), Seychelles (Geisler \& Pardiwalla 2009), France (Pritchard 1987), Germany (Maubach \& Morgan 2001) and South Africa (Gxilishe 1993) have all concluded that, in general, boys underperform in language learning, and that girls achieve better results in language subjects than boys. If boys are underperforming in language subjects, their performance in other learning areas may also be affected because language is essential for all learning. Boys' learning, and in this case their writing, is thus a key area to research. As Daly (2002) argues:

Boys mostly feature as the objects of research, on whom alternative practices are being trialed, than being measured in terms of their writing behaviour in class, or teachers' perceptions of their improved disposition towards writing (p. 4)

This study attempted to engage boys as subjects and agents of writing through the interactive questionnaire.

\section{Teaching boys writing}

The literature indicates differences between boys and girls regarding language learning (Gxilishe 1993; Pavy 2006; Pritchard 1987; Van de Gaer et al. 2009). Carr and Pauwels (2005) highlight the socialisation factor in determining boys' subject choices and, because languages are often considered girl-appropriate subjects, boys' neglect of languages may be a way for them to affirm their masculinity (Scantlebury 2009). Smith and Wilhelm's (2002) seminal book on reading and young men in the American context, Reading Don't Fix No Cherys, points to this socialised gender divide. Regarding boys' disregard of languages, Carr and Pauwels (2005) found that some boys saw language learning as irrelevant for their future.

In addition to socialisation factors, the manner in which boys and girls experience and respond to writing activities differs. Because of a range of social and developmental differences between boys and girls (King \& Gurian 2006; Sax 2005), Weil (2008) motivates for separate classes for boys and girls and Sax (2005) argues in favour of separate schools. Because of contextual factors such as lack of resources and shortage of space, it may not be possible for public schools to have separate classes or same-sex seating. Carr and Pauwels (2005) state that teachers need to acknowledge that boys and girls have different learning needs, and change their teaching methodology where necessary. To assist teachers who teach mixed sex classes, King and Gurian (2006) draw on research on gender differences in cognition and in classroom interaction. They suggest that teachers use same-sex seating arrangements in the classroom and propose the following instructional features to make the writing classroom more boy-friendly. Firstly, experiential and kinaesthetic learning opportunities can be increased by planning activities that keep boys energised, attentive, promote healthy competition and keep boys moving around. Secondly, addressing boys' visualspatial needs with activities like story boards or drawing pictures will help them to put down on paper what they are thinking. Thirdly, because boys and girls have different 
interests and because boys have a strong desire to choose their own topics (Higgins 2002), teachers should provide options that allow for self-direction. Moreover, they should make activities purposeful by connecting them to real-life situations. This is supported by Smith and Wilhelm $(2002,2014)$ who argue for authentic problem-solving classroom tasks that will engage boys in reading and writing. Lastly, teachers should seek out male role models, which may also include older respected male learners, to visit the class and share their learning experiences.

Whilst the various factors regarding gender and writing mentioned above may not be generalisable to the South African context, the difference between boys' and girls' language performance is similar in South Africa than in the rest of the world. This indicates a possible problem with engaging boys' interest in language activities (including writing) and suggests the possibility of developing research strategies that engage boys actively in considering their own writing development. This study thus generated exploratory strategies, suggested by international scholarship but adapted to the local context, in the form of an interactive questionnaire to inquire into boy's own perceptions of their writing.

\section{Conducting research with children}

Eliciting children's perceptions and experiences can be of value to research because children provide original insights into their daily lives that are free from adult interpretations (Laws \& Mann 2004). Researchers use a variety of methods when conducting research with children, which should be child-appropriate. For instance, Shaw, Brady and Davy (2011:20) provide the following general ideas to consider when conducting research with children:

- Data collection must be brief and concise because children have a shorter attention span than adults.

- An informal, open environment must be created.

- The approach should emphasise that there are no correct or incorrect answers.

- Short questions and simple language should be used whilst abstract concepts ought to be avoided.

- Researchers should be aware that questions may not be interpreted as intended.

- Data collection tools must be accessible (content, length, format and language) based on the age and intellect of the children.

- Piloting of the data collection tools is essential.

Whilst various methods are advocated for conducting research with children, including focus groups (Hennessey \& Heary 2005), observations (Christiansen, Bertram \& Land 2010; Mather 2012) and participatory methods (Shaw et al. 2011), this study focuses on the use of an interactive questionnaire.

\section{The questionnaire}

A questionnaire is a list of questions, either open-ended or close-ended or both, which the participants answer to elicit attitudes, beliefs or reactions (McMillan \& Schumacher 2001). An activity-based questionnaire was created for this study of boys' writing in view of the following factors. Firstly, boys tend to have a shorter attention span (than girls) and need to move around periodically (King \& Gurian 2006); therefore, the data collection method should allow for variety, choice and movement. Secondly, they need to see the purpose of what they are doing and be interested enough in the process to provide meaningful responses. Shaw et al. (2011) state that, to maintain interest when collecting data from children, the researcher must be clear at the outset about what is expected from their participation. Lastly, Shaw et al. (2011) caution against making unreasonable demands on their time. In the case of this study, negotiating time with the boys' teachers to collect data from them was challenging because there was not much time to spare given the sequence and pace of the CAPS. Contextual factors, pre-pubescent boys' learning preferences and different data collection methods were considered and evaluated (the discussion of each is provided below) which led to the design of the activity-based questionnaire.

\section{Methodology Participants and research setting}

The sample for the study consisted of 39 Grade 6 boys and two English HL teachers. School A was a formerly Indian school which is now racially and linguistically mixed. Sixteen Indian and five black African boys from this school participated in this study. The 18 boys from School B were all black Africans - their mother tongue is isiZulu, but they were learning English at HL level. The focus of the study was the boys' and their teachers' experiences, with particular emphasis on their perceptions and challenges, of teaching and learning writing using the process-genre approach.

\section{Procedure: Conducting research with boys}

Because of the need for self-reported data pertaining to the participants' experiences and challenges of the writing programme, in-depth interviews were conducted with the teachers. The initial plan was to interview the boys as well. However, after reviewing the literature related to boys' learning preferences and what an interview entails, this was reconsidered.

Eliciting rich, in-depth data would have meant interviewing each boy for not less than $30 \mathrm{~min}$ on two occasions. As Lobe et al. (2008:33) contend, 'a standard, lengthy series of questions and answers may not work as well for children as for adults'. They suggest a variety of active strategies to engage children, including drawing pictures, role play and pen-and-paper exercises. Supporting this, Fargas Malet et al. (2010) recommend using a wide range of activities and using a mixture of materials and techniques when conducting research with children. Besides retaining the boys' interest, in this study, there were also logistical challenges that made interviewing problematic. Securing time for so many interviews would have disrupted the normal teaching 
programme. Thus, there was a need for an alternative method to elicit the required data from the boys.

A second option was to plan focus groups for the boys to share their perspectives on and experiences of the manner in which they learn writing. Whilst focus groups can work well with children if they are made enjoyable and interesting, if the children are given breaks (Fargas Malet et al. 2010) and if they are sensitively and ethically incentivised (Gibson 2007), the constraints of the timetable once again mitigated against this. It would have meant allocating four groups of about six boys each at least two 30-min sessions. Unfortunately, because of the pace of the CAPS and mandatory extracurricular activities, the participating teachers did not have sufficient time to allocate for focus groups and follow-up discussions with the boys.

Finally, the idea of using questionnaires was considered, which others have found can be effective with children if designed and administered appropriately (Bell 2007; De Leeuw 2011). It was surmised that this data collection tool would work best as it could be administered to all the boys at the same time with the researcher present to provide clarity if there were any misunderstandings. The use of open-ended questions would certainly have elicited indepth responses but expecting pre-pubescent boys to sit still and provide responses to a questionnaire may not have elicited trustworthy responses, as they may have rushed to complete the questionnaire without really thinking about their responses. Closed-ended questions, on the other hand, that required the boys to simply choose the most appropriate response may not have been stimulating for them.

\section{Design of the activity-based questionnaire}

These considerations led to the design of an activity-based questionnaire that would be enjoyable for the boys, allow for movement, cater to the boys' different learning styles and not be too time-consuming. The specific purpose of the questionnaire as a data collection instrument was to gain insight into how the boys perceived and experienced a cycle of the writing programme and the challenges that they may have encountered when writing. The questionnaire consisted of four sections. The first section was 'General', which dealt with biographical information. The second section was 'School' where the boys would provide insight into their school experiences such as their best friends, favourite subjects and favourite and least favourite aspects of school. The third section was 'English' to determine the boys' favourite and least favourite aspects of learning English. The last section was 'Writing'. Here, boys indicated the genres of writing that they did in class, their favourite and least favourite types of writing, and difficulties that they experienced when completing a piece of writing. They also had to draw a picture of a writing lesson. The purpose of the drawing exercise was to elicit visual representations of how the boys experienced a cycle of the writing process. Shaw et al. (2011:23) state that drawings are best used for capturing the participants' ideas or thoughts to supplement interview or focus group data, and that each drawing must be accompanied by a caption so that the participating children are given the opportunity to explain their drawings. Thus, the researchers included a block at the bottom of the page allocated for the drawing, for the boys to write a paragraph to explain the drawing that represented their learning experience in the writing class.

The draft questionnaire was three pages long, with a blank fourth page for the boys to draw their pictures and write a paragraph. Three workstations and a help desk were created in the classrooms where the questionnaire was administered. At the first workstation, the boys would come to complete parts of the questionnaire that required them to write answers using pens. The second workstation contained crayons and coloured pens for the boys to come to if they needed to colour in or draw. The last workstation was for the boys to come and use stickers for the different parts of the questionnaire. This allowed for movement, which, according to King and Gurian (2006), is necessary to cater for boys' tendency to be restless and fidgety.

Each workstation had a symbol and these symbols also appeared on the questionnaire. Depending on the workstation that the boys had to go to, the relevant symbol appeared. For example, the star image in Figure 1 was the symbol for station two. Thus on this questionnaire, wherever the boys saw this symbol, they would have to go to station two to use the stickers provided. An example of this taken from the questionnaire is provided in Figure 2.

The questionnaire assumed that the boys would be able to read and understand the instructions; thus, it was vital to ensure that the instructions were unambiguous, clear and pitched at the appropriate level. For instance, instead of using the word genre, types of texts was used, and instead of using descriptive, narrative, expository and visual, simpler terms such as stories, descriptions, news reports and adverts

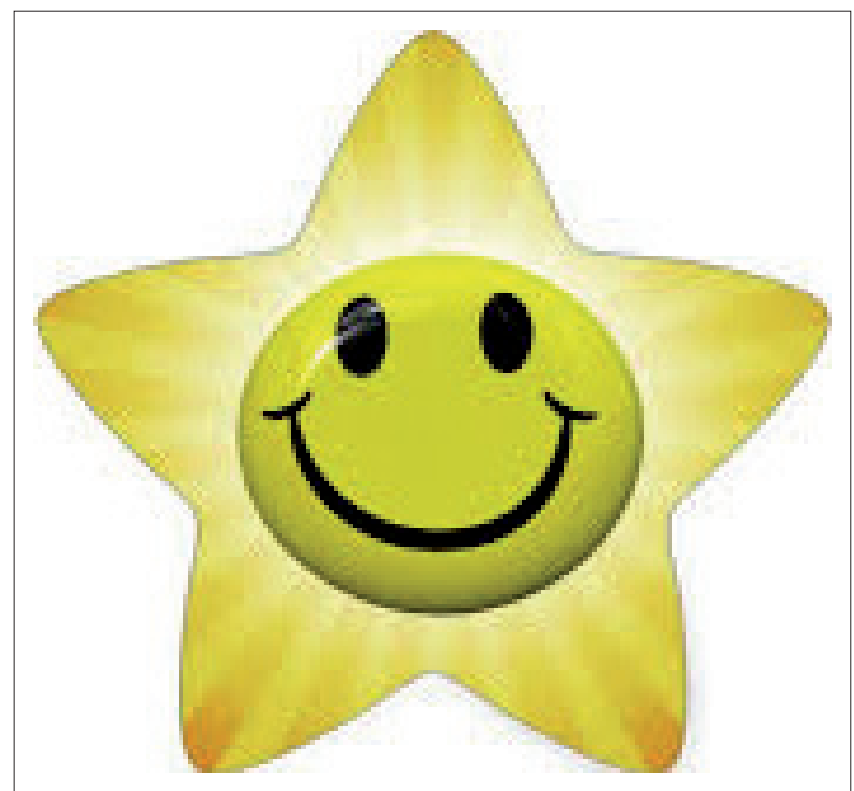

FIGURE 1: Symbol used for station 2. 
were used. The font size was also carefully considered to ensure that the boys would be able to read the instructions with ease and not risk missing any questions. A different font type for each workstation was used so that the stations would be easily identifiable.

Another consideration taken from King and Gurian (2006) was giving the boys the freedom to make their own choices. Thus, in the pilot questionnaire, they could choose their favourite stickers and use their favourite colours for certain aspects. In this way, some effects of socialisation on these boys could also be observed because colours like pink are considered to be more female-oriented colours, whilst blue is a favourite for boys. There was also a range of stickers provided; hearts, stars, flowers, cars and other motor vehicles, as well as stickers of handbags, shoes and cosmetics. It was interesting to see which of the stickers and colours the boys chose.

\section{Piloting and adapting the questionnaire}

The questionnaire was piloted at a public school with eight Grade 6 boys. This was crucial for testing whether the design and content of the questionnaire, including the wording of tasks, questions and instructions (De Leeuw 2011), and the process of administering it were appropriate. The researcher was introduced to the boys by their English teacher before she left the classroom. This happened during an English period of $60 \mathrm{~min}$. The researcher proceeded to explain the purpose of the questionnaire, how they would use the workstations to complete it and the general rules to maintain order. The workstations were set up on the far ends of the classroom and the help desk was in the front by the teacher's table. The boys moved around freely and easily and seemingly had fun with the stickers and colours. They took about $1 \mathrm{~h}$ to complete the questionnaire.

The piloting phase showed that including incentives in the process and an element of competition engaged the interest of the boys. King and Gurian (2006) state that boys enjoy healthy competition. The researcher added instructions that would make the boys look for certain items at the different workstations; whoever found the item was instructed to bring it to the help desk to claim a reward. The reward instructions helped to ensure that the boys were reading all the questions and instructions carefully. This phase also indicated that boys responded well to having choices, confirming King and Gurian (2006) insight that boys prefer to make their own decisions. The instruction pertaining to their favourite subjects was changed to allow the boys to choose their favourite stickers to indicate their favourite subjects. At the workstation, a selection of car, motor vehicle, handbag, cosmetic and shoe stickers was included. In addition to allowing for choice, it allowed for the researcher to see which stickers the boys would choose, as with their favourite colours and the colour flower sticker that they chose to stick on their age, as can be seen in Figure 3.

Following the pilot, some design modifications were made to the questionnaire. For instance, the question in Figure 3 previously read as indicated in Figure 4. This change was made to allow for freedom of choice, as explained above. Modifications were also made with regards to the formatting and font size - this was done to improve readability and ease of use.

\section{Findings \\ Participants' response to the questionnaire}

The final questionnaire contained four sections. Once the excitement over the stations, colours and stickers subsided, the boys in both schools managed most of the first section, 'General' with ease. They were unsure of what to do at first, but, after reading and following the instructions, they managed fairly independently. However, all the boys in School B and one isiZulu speaking boy in School A came to the help desk as they needed assistance with writing their address (the reason being that in many of the outlying areas where they live, there are no street names or house numbers). These learners were

\begin{tabular}{|l|l|l|l|l|l|}
\hline Pick your favourite sticker and stick it on your favourite subject. Then, stick a green star on your least favourite subject. & SS & NS \\
\hline ENG & AFRIK & ZULU & MATHS & LIFESKILLS & \\
\hline
\end{tabular}

FIGURE 2: Question with subject options.

Pick your favourite sticker and stick it on your favourite subject. Then,stick a green star on your least favourite subject.

\begin{tabular}{|l|l|l|l|l|l|}
\hline & AFRIK & MATHS & SS & LIFESKILLS & NS \\
\hline
\end{tabular}

FIGURE 3: Question with subject options.

\begin{tabular}{|l|l|l|l|l|l|}
\hline \multicolumn{2}{|l|}{ Stick threesmiley faces on your favourite subject. Then, stick three sad faces on your least favourite subject. } \\
\hline & AFRIK & ZULU & MATHS & LIFESKILLS & SS \\
ENG & & & NS \\
\hline
\end{tabular}

FIGURE 4: Question with subject options. 
told to write the area where they lived. The reason for asking the boys where they lived was to assist with determining their cultural and socio-economic status. Some boys came to the help desk to ask what they should do if no-one helped them at home with their homework, thus 'No-one' should have been included as an option for them to colour in.

The second section entitled 'School' dealt with aspects like the part of school that they enjoyed most and least, their favourite and least favourite subjects and who their best friend was. This section was also accomplished with ease by the boys but, in both schools, when the researcher was walking around, she noticed that many learners had put a sticker by their favourite subject but omitted the green star on their least favourite sticker. A possible reason for this was that the instruction was too long and after engaging with the first part, the boys forgot to go back to complete the second part. Perhaps, this question should have been split into two questions as follows (see Figures 5 and 6).

The next section dealt with English and asked the learners about their favourite and least favourite aspect of learning English as well as the genre that they most and least enjoyed reading. Here, again, the question should have been split as explained in the paragraph above as some boys omitted the second part of the instruction. Orals and listening to stories were most boys' least favourite aspect of English, with only two boys choosing writing. On the other hand, reading was a favourite for most boys, whilst seven boys chose writing as a favourite. In School A, four boys chose all the aspects as their favourite. This could be because they indeed enjoyed all aspects of learning English or that they enjoyed sticking the stickers because in the second section of the questionnaire, these same boys did not select English as their favourite subject. The effects of socialisation and issues of masculinity were evident in the second question of this section because most boys chose action, adventure and comics as their favourites with only two boys from School A and seven boys from School B choosing fairy tales and romance. Two boys from School B picked 'other' as an option but did not write the genre that they instead enjoyed reading. This was because there was no instruction or space provided on the questionnaire for them to write the other genres. The findings suggest that this part could have been presented as indicated in Figure 7 and Figure 8.

The boys had to provide information about their writing experiences. They were asked about the types of writing that they did in class, their favourite and least favourite types of writing and the part of writing that they found most difficult. Further to this, they had to draw a picture reflecting their teacher teaching them writing and write a paragraph to explain what was happening in the picture that they drew. The answers for the types of writing that they did in class were not consistent considering they were all in the same class (in the school that they attended) and taught by

\begin{tabular}{|l|l|l|l|l|l|}
\hline \multicolumn{9}{|l|}{ Pick your favourite sticker and stick it on your favourite subject. } & MATHS & LIFESKILLS \\
\hline ENG & AFRIK & ZULU & & SS \\
\hline
\end{tabular}

FIGURE 5: Question with subject options.

\begin{tabular}{|l|l|l|l|l|l|}
\hline \multicolumn{2}{|l|}{ Stick a green star on your least favourite subject. } & MATHS & SIFESKILLS & SS \\
\hline ENG & AFRIK & ZULU & & NS \\
\hline
\end{tabular}

FIGURE 6: Question with subject options.

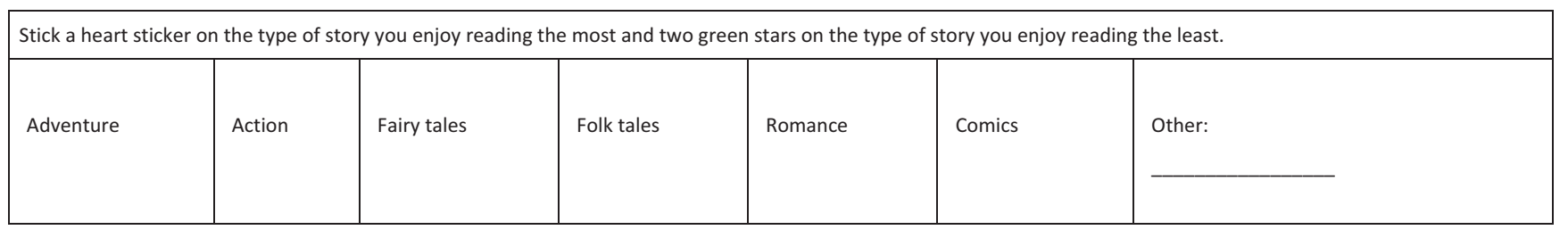

FIGURE 7: Question with types of stories.

Stick two green stars on the type of story you enjoy reading the least.

\begin{tabular}{|l|l|l|l|l|l|l|}
\hline & & & & & Comics & Other: \\
\hline
\end{tabular}

FIGURE 8: Question with types of stories. 
the same teacher. For instance, in School A, most boys selected almost all the genres provided but three selected only stories, letters and advert. In School B, all the boys selected stories, plays and poems but each had a different variation of the other genres. A possible reason for this could be that the boys coloured in the ones that stood out in their minds or that they remembered having written, so this is not necessarily an accurate indication of the genres that they learnt how to write in class. In addition, some picked favourite and least favourite types of writing that were not compatible with the list that they provided for the types of writing that they did in class.

Thus, triangulation was important: teachers were asked about the types of writing that they taught their learners and the learners' books were analysed to see the writing that they did. Nevertheless, the responses that the boys provided for these questions were of value as they indicated the types of writing that the boys were most familiar with.

Most boys found spelling, punctuation, thinking what to write about and planning most difficult when writing. Two boys in School B wrote the following: 'writing without knowing what to write about' and 'writing your own story'. This was interesting because their teacher did not give them a topic to write about. Instead, they were told to write a story about anything, in other words, they had to choose their own topic.

Finally, the boys had to draw pictures of a writing lesson and had to write a paragraph about how they learnt writing. The boys did not put much effort into the completion of this section and many expressed that they did not enjoy drawing, could not draw well or did not know what to draw. The boys had to be reminded to complete this part of the questionnaire. After analysing their completed questionnaires, the drawings did not contribute much to the findings, so this aspect could have been omitted (or needed to be approached differently). Most of the drawings depicted learners seated, with a teacher standing in the front of a chalkboard. With regard to the paragraphs, the boys appeared not to know what to write and possibly did not have the vocabulary to complete the paragraph. This is telling, in that the boys should have been familiar with the stages of the writing cycle, as their teachers stated during the interviews that it was how they developed writing since the beginning of the year. Additionally, the teachers reported that these learners produced a variety of texts throughout the year, but the boys were unable to write about any of these texts. Instead of paragraphs, the boys, who attempted to write something, wrote a few sentences that related to writing but not to how they learnt writing. Most of the boys left this section blank.

\section{Discussion}

\section{Using an interactive questionnaire with boys:} Lessons learnt

This section discusses the insights arising from using an interactive questionnaire with boys in relation to the content, process, design and findings. Broadly speaking, six key areas that need to be considered in the use of an interactive questionnaire were identified, namely: the need for clear and simple language, the importance of affect, supporting and scaffolding the process, using incentives, multi-modality and the need for triangulation of findings. Each of these areas will be discussed in more detail below.

\section{Content lesson: Simplicity, accessibility and present-focus}

The content issues arising from using the questionnaire confirmed previous findings that the language level and accessibility of the questionnaire are crucial. For example, formulating the questions simply and with words that learners understand (Bell 2007; De Leeuw 2011) are paramount. Importantly, this study found that questions should not be double-barrelled, as learners consistently neglected to respond to the second part of the question. In addition, questions with a current focus seemed to be answered in more detail and more accurately than those requiring retrospection. This supports Bell's (2007) finding that the ability to reflect is not as well developed in children as it is in adults.

\section{Process lesson: Participants' affective responses to questionnaire}

From the research process, it became apparent that how the boys felt about doing the questionnaire was important for its effectiveness as a research instrument. A non-threatening, non-intimidating, enjoyable environment was created to ensure that the boys were comfortable and at ease - the underlying idea being that they would have no reason to invent responses or not to respond. In both schools, the boys' reactions indicated that they most enjoyed choosing and using the stickers as they spent the most time at this station. It was interesting to note that all the boys picked the car and motorbike stickers as their favourite. In School A, the boys took out their sticker albums to show the researcher their collections and asked if they could share the leftover stickers.

Illeris (2009) argues that all learning involves not only a 'content' dimension but also an 'incentive' dimension that is concerned with motivation, emotions and volition. Both these dimensions are informed by an 'interaction' dimension, which concerns the relations between participants. This theory of learning pointed towards the importance of considering the relation amongst content, incentive and interaction in using the questionnaire. The study found that the conducive environment and supportive interactions contributed to creating positive feelings towards the task.

\section{Process lesson: Supporting and scaffolding the process}

Scaffolding and support are key considerations for effective language teaching (Rose 2004) and proved important in administering the questionnaire. In School A, the boys came to the help desk to ask many questions pertaining to the purpose of the questionnaire and to find out more about who the researcher was and what she was doing. Thus, when the researcher went to School B, she spent more time 
on introducing herself, the questionnaire and its purpose. Some boys in this school definitely needed more assistance with understanding what to do but, by the end of the first section, most were able to follow the instructions independently. A few boys in this school were unable to read the instructions, so the researcher assisted some with completing the whole questionnaire, whilst others asked their peers for assistance. The presence of their teacher did not hinder the process. Instead, she was a great help in terms of maintaining order and seeing to the girls. She also constantly reminded the boys of the importance of being honest and taking their time to think about their responses to provide accurate information. In both schools, the girls were very disappointed that they were not a part of the process but enjoyed colouring-in the mandalas that the researcher provided to keep them occupied.

The researcher also found that walking around and providing assistance was helpful as opposed to waiting for the boys to come to her at the help desk. Although boys did come to the help desk to ask questions, going to them was beneficial particularly for the boys who were shy or afraid of seeming unintelligent for not knowing what to do.

\section{Process lesson: Using incentives to engage participants}

Promoting healthy competition, as suggested by King and Gurian (2006) and drawing on Illeris' (2009) 'incentive dimension of learning', by using the unexpected instructions for prizes, was particularly beneficial because it prompted boys to read instructions carefully and broke the ice in getting them to come to the help desk. An important consideration arising from the study is that incentives should stimulate engagement but not become ends-in-themselves that detract from the primary purpose of data collection.

\section{Design lesson: Using appropriate multi-modality}

Multi-modality played an important role in the design and administration of the interactive questionnaire. Fleming (1995) elaborates four learning styles: visual, auditory, reading or writing and kinaesthetic (commonly known as VARK). The questionnaire used multiple modes of communication and interaction to account for individual learning styles. These included written, visual, kinaesthetic, interpersonal and interactional modes. These varied modes not only accommodated the boys' different learning styles but also helped to keep the boys engaged so that they completed the questionnaire and produced rich data. Symbols and pictures were used and the boys were expected to read and follow the instructions, provide written responses, colour in some responses, draw pictures and stick stickers on others. The questionnaire also allowed for the boys to move around to the different stations, to the help desk and whilst moving around, there was animated interaction amongst the boys about which section they were at, which stickers they chose, which boy picked the best sticker and so on, which again foregrounded the competitive nature of the boys. Finally, by including a creative task (in which boys had to depict how they learnt to write via their own artwork, and had to describe their drawings in writing), the researchers hoped to gain a deeper understanding of learners' experiences of and opinions about the writing cycle (i.e. planning, drafting, revising, editing and publishing) that was used to teach them. It was clear though that the boys were unable to respond to this task; most likely as a result of their general dislike of drawing, and their limited understanding of what the various stages of the writing cycle entail.

Using a multi-modal approach recognises that children operate in a multi-modal culture in which they are used to interacting with various media, particularly through cell phones, gaming and other audio-visual technologies (Tan \& Guo 2009). As Vincent (2006:51) argues, 'Some children need multi-modal scaffolding in order to communicate ideas effectively'. However, in the South African context, access to multi-modal technologies is uneven, especially regarding computer-based technologies. With this in mind, the use of multi-modality has to be contextually appropriate and a textbased but interactive and visually rich format was selected so as not to exclude learners.

\section{Findings lesson: The need for triangulation}

The questionnaire provided some insight into boys' writing preferences, for example, their greater enjoyment of adventure, comics and action genres rather than fairy stories and romance. In addition, the responses to the questionnaire also indicated that learners found 'spelling', 'punctuation', 'thinking what to write about' and 'planning' most difficult when writing, which was born out in lesson observations, interviews with teachers and analysis of workbooks. However, an analysis of the findings also revealed that not all their responses were necessarily reliable indicators. For example, the incentive of getting prizes and the process of using stickers might have overshadowed their attention to the actual content. This confirms Scott's (2000) contention that children's answers may reflect biases such as social desirability, context effects and acquiescence bias. The findings from a questionnaire such as the one described in this article thus have to be carefully triangulated using other methods, including classroom observation, interviewing teachers and analysing learners' workbooks.

\section{Limitations and recommendations}

As we acknowledged above, this particular questionnaire was designed with the target group in mind and it therefore might not be generalisable as a research instrument in different contexts. However, the lessons learnt could have value for teachers and researchers in designing their own instruments to investigate boys' writing. In addition, we recommend that a questionnaire like this should be used together with other methods to enhance reliability of findings. In South African and African contexts, further research is needed to ascertain boys' perceptions of and engagement in their own writing, as well as comparative research on boys' and girls' writing. In particular, future research should attend to the finding that the boys were unable to describe or reflect on the different stages of the writing process that had been 
used as an instructional method by their teachers. This is concerning and leads to several questions about how writing instruction unfolds in the average South African classroom, and whether the guidelines for writing instruction in the CAPS meet the needs of teachers and learners.

\section{Conclusion}

This article focused on the use of an interactive questionnaire to explore Grade 6 boys' attitudes towards, and experiences of, writing. The article identified factors related to the content, process, design and findings of the questionnaire. Regarding content, it was found that questions and instructions had to be formulated at an appropriate level. The process of administering the questionnaire revealed that the interactive nature of the instrument catered for the boys' need for movement and activity, and that promoting healthy competition through the use of hidden items helped to motivate and energise them. The multi-modal design of the questionnaire (written, visual, kinaesthetic and interpersonal) accommodated a range of skills and learning styles. The questionnaire generated some useful findings regarding the learners' perceptions of their writing, but the unevenness of their responses also pointed to the importance of triangulation of sources and methods. The use of this questionnaire also indicated the importance of providing clear explanation and instructions at the beginning of the process, and continuing support and encouragement throughout. Creating a conducive, non-threatening environment, enlisting the assistance of the teacher and developing a supportive relationship between researcher and participants also proved important for the boys' participation and the effectiveness of the data collection process. What the exercise also showed was that careful consideration of the research participants' interests, age, gender and cultural motivations is an important part of affording them agency in the research process.

\section{Acknowledgements Competing interests}

The authors declare that they have no financial or personal relationship(s) that may have inappropriately influenced them in writing this article.

\section{Authors' contributions}

N.M. planned and conducted the research, analysed the results and drafted the manuscript. P.R. supervised the research, assisted with the conceptualisation and analysis of the results and edited and developed the manuscript.

\section{References}

Bell, A., 2007, 'Designing and testing questionnaires for children', Journal for Research in Nursing 12(5), 461-469. https://doi.org/10.1177/1744987107079616

Carr, M.J. \& Pauwels, A., 2005, Boys and foreign language learning: Real boys don't do languages, Palgrave Macmillan, Basingstoke, Hampshire.

Christiansen, I., Bertram, C. \& Land, S., 2010, Understanding research, 3rd edn., Faculty of Education UKZN, Pietermaritzburg.

Daly, C., 2002 Literature search on improving boys' writing, viewed 02 July 2015, from http://dera.ioe.ac.uk/4781/
De Leeuw, E.D., 2011, 'Improving data quality when surveying children and adolescents: Cognitive and social development and its role in questionnaire construction and pretesting', Report prepared for the Annual Meeting of the Academy of Finland: pretesting', Report prepared for the Annual Meeting of the Academy of Finland: and Young People, 10-12 May, Naantali, Finland, viewed 11 September 2017, from and Young People, 10-12 May, Naantali, Finland, viewed 11 September 2017, from http://www.aka.fi/globalassets/awanhat/documents/tiedostot/lapset/ presentations-of-the-annu
adolescents_de-leeuw.pdf

Department of Basic Education (DBE), 2011a, National Curriculum Statement (NCS): Curriculum and Assessment Policy Statement (CAPS): Home language: Intermediate phase, Government Printing Works, Pretoria.

Department of Basic Education (DBE), 2011b, Report on the annual national assessments of 2011, Government Printing Works, Pretoria.

Department of Basic Education (DBE), 2012, Report on the annual national assessments of 2012, Government Printing Works, Pretoria.

Department of Basic Education (DBE), 2013, Report on the annual national assessments of 2013, Government Printing Works, Pretoria.

Department of Basic Education (DBE), 2014, Report on the annual national assessments of 2014, Government Printing Works, Pretoria.

Fargas Malet, M., McSherry, D., Larkin, E. \& Robinson, C., 2010, 'Research with children: Methodological issues and innovative techniques', Journal of Early Childhood Research 8(2), 175-192. https://doi.org/10.1177/1476718X09345412

Fleming, N.D., 1995, 'I'm different; not dumb. Modes of presentation (VARK) in the tertiary classroom', in A. Zelmer (ed.), Research and development in higher education, Proceedings of the 1995 Annual Conference of the Higher Education and Research Development Society of Australasia (HERDSA), vol. 18, pp. 308-313, HERDSA, Hammondville, Australia.

Geisler, G. \& Pardiwalla, M., 2009, Gender socialisation in the home: Its impact on boys' achievement in primary and secondary schools, viewed 02 February 2015 , from http://www.afdb.org

Gibson, F., 2007, 'Conducting focus groups with children and young people', Journal of Research in Nursing 12(5), 473-483. https://doi.org/10.1177/1744987107079791

Graham, L., 2003, 'Writing journals: An investigation', Literacy 37(1), 39-42. https:// doi.org/10.1111/1467-9345.3701008

Gxilishe, S., 1993, 'Sex differences in linguistic ability: A case for Xhosa', South African Journal of Applied Language Studies 2(2), 11-19. https://doi.org/10.1080/10189 203.1993.9724625

Hennessey, E. \& Heary, C., 2005, 'Exploring children's views through focus groups', in S. Green \& D. Hogan (eds.), Researching children's experiences: Approaches and methods, pp. 236-252, Sage, London.

Higgins, C., 2002, 'Using film text to reach reluctant writers', English in Education 36(1), 25-37. https://doi.org/10.1111/j.1754-8845.2002.tb00752.x

Howie, S., Van Staden, S., Tshele, M., Dowse, C. \& Zimmerman, L., 2012, Progress in International Reading Literacy Study 2011. South Africa's children's literacy achievement, Summary report, Centre for Evaluation and Assessment, University of Pretoria, Pretoria.

Illeris, K., 2009, 'A comprehensive understanding of human learning', in K. Illeris (ed.), Contemporary theories of learning: Learning theorists...in their own words, pp. 7-20, Routledge, London.

King, K. \& Gurian, M., 2006, 'Teaching to the minds of boys', Teaching to Student Strengths 64(1), 56-61.

Laws, S. \& Mann, G., 2004, So you want to involve children in research? A toolkit supporting children's meaningful and ethical participation in research relating to violence against children, Save the Children, Stockholm.

Lobe, B., Livingstone, S., Olafsson, K. \& Simões, J.A., 2008, Best practice research guide: How to research children and online technologies in comparative perspective, EU Kids Online, London.

Long, C. \& Zimmerman, L., 2008, Reading beyond the lines: Developing South African Foundation Phase learners' higher order reading literacy skills, Centre for Evaluation and Assessment, University of Pretoria, Pretoria.

Mather, N., 2012, Making the CAPS fit: An exploration of the reading development strategies of three Intermediate Phase language educators in a rural KwaZuluNatal school, Unpublished masters dissertation, University of KwaZulu-Natal, Pietermaritzburg.

Maubach, M. \& Morgan, C., 2001, 'The relationship between gender and learning style amongst A level modern students', Language Learning Journal 23(1), 41-47. https://doi.org/10.1080/09571730185200081

McMillan, J.H. \& Schumacher, S., 2001, Research in education. A conceptual introduction, 5th edn., Longman, New York.

Nasvaria, I., Pascoe, M. \& Kathard, H., 2011, “'It's not just the learner, it's the system!" Teacher's perspectives on written language difficulties: Implications for speechlanguage therapy', South African Journal of Communication Disorders 58(2), 95-104.

Pavy, S., 2006, 'Boys learning languages', Language Learning Journal 41(1), 2-11.

Pretorius, E.J., 2002, 'Reading and applied linguistics - A deafening silence?', South African Applied Linguistics and Applied Language Studies 20, 91-103. https://doi. org/10.2989/16073610209486300

Pritchard, R., 1987, 'Boys' and girls' attitudes towards French and German', Educationa Research 29(1), 65-72. https://doi.org/10.1080/0013188870290108

Rose, D., 2004, 'Sequencing and pacing of the hidden curriculum: How indigenous children are left out of the chain', in J. Muller, A. Morais \& B. Davies (eds.), Reading Bernstein, researching Bernstein, Routledge, London.

Rule, P. \& Land, S., 2017, 'Finding the plot in South African reading education', Reading \& Writing 8(1), a121. https://doi.org/10.4102/rw.v8i1.121 
Sax, L., 2005, Why gender matters, Doubleday, New York.

Scantlebury, K., 2009, Gender role stereotyping, viewed 10 February 2015, from www. education.com

Scott, J., 2000, 'Children as respondents. The challenge for quantitative methods', in P. Christensen \& A. James (eds.), Research with children. Perspectives and practices, pp. 98-119, RoutledgeFalmer, London.

Shaw, C., Brady, L.M. \& Davy, C., 2011, Guidelines for conducting research with children and young people, NCB Research Centre, London.

Smith, M. \& Wilhelm, J., 2002, Reading don't fix no Chevys: Literacy in the lives of young men, Heinemann, Portsmouth, $\mathrm{NH}$.

Smith, M. \& Wilhelm, J., 2014, 'Reading don't fix no Chevys (Yet!)', Journal of Adolescent and Adult Literacy 58(4), 273-276. https://doi.org/10.1002/jaal.361
Tan, L. \& Guo, L., 2009, 'From print to critical multimedia literacy: One teacher's foray in new literacies practices', Journal of Adolescent and Adult Literacy 53(4), 315324. https://doi.org/10.1598/JAAL.53.4.5

Tan, L. \& Zammit, K. (eds.), 2016, Teaching writing and representing in the primary school years, Pearson, Melbourne.

Van de Gaer, E., Pustjens, H., Van Damme, J. \& de Munter, A., 2009, 'School engagement and language achievement: A longitudinal study of gender differences across secondary school', Merill-Palmer Quarterly 55(4), 373-405. https://doi.org/10.1353/mpq.0.0034

Vincent, J., 2006, 'Children writing: Multimodality and assessment in the writing classroom', Literacy40(1),51-57.https://doi.org/10.1111/j.1467-9345.2006.00426.x

Weil, E., 2008, Teaching boys and girls separately, viewed 27 December 2013, from http://www.nytimes.com 